\title{
ANÁLISE DE CONTEÚDO, ANÁLISE DO DISCURSO \\ E ANÁLISE DE CONVERSAÇÃO: \\ ESTUDO PRELIMINAR SOBRE DIFERENÇAS CONCEITUAIS E \\ TEÓRICO-METODOLÓGICAS
}

\author{
CONTENT ANALYSIS, DISCOURSE ANALYSIS, \\ AND CONVERSATION ANALYSIS: \\ PRELIMINARY STUDY ON CONCEPTUAL AND \\ THEORETICAL METHODOLOGICAL DIFFERENCES
}

\author{
Recebido em: 09/10/2015 A Aprovado em: 21/12/2015 \\ Avaliado pelo sistema double blind review \\ Editora Científica: Claudia Stadtlober \\ DOI 10.13058/raep.2016.v17n2.323
}

\section{ANDERSON TIAGO PEIXOTO GONÇALVES adm.andersontiago@gmail.com UNIVERSIDADE FEDERAL DO RIO GRANDE DO NORTE}

\begin{abstract}
RESUMO
Este ensaio teórico tem como objetivo refletir sobre três modelos de interpretação de textos utilizados na pesquisa qualitativa, muitas vezes, confundidos em seus conceitos e suas metodologias: Análise de Conteúdo, Análise do Discurso e Análise de Conversação. Após a apresentação dos seus conceitos, propõe-se discutir, preliminarmente, acerca das diferenças teórico-metodológicas perceptíveis entre eles. Foi realizada uma pesquisa bibliográfica para subsidiar a discussão conceitual e teórico-metodológica. Verificou-se que os modelos revelam diferenças relacionadas ao tipo de estratégia utilizada no tratamento dos textos, ao tipo de abordagem e à postura teórica em que se enquadram.

Palavras-chave: Pesquisa qualitativa; Modelos de interpretação de textos; Análise de conteúdo; Análise do discurso; Análise de conversação.

\footnotetext{
ABSTRACT

This theoretical essay aims to reflect on three models of text interpretation used in qualitative research, which is often confused in its concepts and methodologies (Content Analysis, Discourse Analysis, and Conversation Analysis). After the presentation of the concepts, the essay proposes a preliminary discussion on conceptual and theoretical methodological differences perceived between them. A review of the literature was performed to support the conceptual and theoretical methodological discussion. It could be verified that the models have differences related to the type of strategy used in the treatment of texts, the type of approach, and the appropriate theoretical position.

Keywords: Qualitative Research; Models of Interpretation of Texts; Content Analysis; Discourse Analysis; Conversation Analysis.
} 


\section{INTRODUÇÃO}

A interpretação de textos na pesquisa qualitativa, enquanto etapa posterior à coleta de dados, tem como função tanto o desenvolvimento da teoria como o embasamento para a coleta de dados adicionais e decisão de quais casos devem ser selecionados (FLICK, 2009). A interpretação de textos se propõe a buscar dois objetivos opostos: revelar e expor enunciados ou contextualizá-los no texto, assim, levando a um aumento do material textual; ou a reduzir o texto original por meio de paráfrase, resumo ou de categorização.

Conforme Flick (2009), podem-se distinguir duas estratégias de como trabalhar com textos: a codificação de material, que tem o objetivo de categorizar ou desenvolver a teoria; e a análise sequencial do texto, que busca a reconstrução da estrutura do texto e do caso. Na primeira estratégia, encontram-se procedimentos como a codificação teórica, a codificação temática, a análise qualitativa do conteúdo e a análise global; enquanto que, na segunda, constam a análise de conversação, a análise do discurso, a análise de gênero, a análise narrativa e a hermenêutica.

Sabe-se que há uma proliferação de termos para descrever as várias possibilidades de se extrair o significado de comunicações contidas em um texto, ou em qualquer outra forma de comunicação (CHIzzotTi, 20Io). Nesse sentido, a análise de conteúdo, a análise do discurso e a análise de conversação constituem modalidades de interpretação de textos, que, segundo Chizzotti (2010), apoiam-se em diferentes orientações filosóficas e propõem formas de análise fundamentadas nas diversas teorias linguísticas, na semiótica, na hermenêutica, no estruturalismo, no pós-estruturalismo e no interacionismo, a fim de se extrair significados expressos ou latentes de um texto.

Assim, este ensaio teórico tem como objetivo fazer uma reflexão especificamente sobre três modelos de interpretação de textos, ou estratégias de análise de dados, utilizados na pesquisa qualitativa, que, muitas vezes, são confundidos em seus conceitos e metodologias, quais 
sejam: Análise de Conteúdo, Análise do Discurso e Análise de Conversação. Após a apresentação sumarizada dos conceitos teórico-metodológicos de cada um dos modelos, o estudo se propõe a discutir preliminarmente algumas das diferenças perceptíveis entre eles à luz dos achados na literatura especializada. Parte-se, inicialmente, de uma diferenciação geral entre os três modelos, e, na sequência, é desenvolvida uma diferenciação aos pares: Análise de Conteúdo versus Análise do Discurso; Análise de Conteúdo versus Análise de Conversação; e Análise do Discurso versus Análise de Conversação. Para tanto, foi realizada uma pesquisa bibliográfica, recorrendo a livros e artigos científicos, com o intuito de identificar aspectos relevantes para a discussão conceitual e teórico-metodológica.

A importância deste estudo reside no fato de que o quantitativo de pesquisas que utilizam esses modelos de interpretação de textos, de natureza qualitativa, tem-se elevado (DELLAGNELO; SILVA, 2005), principalmente, no campo da produção científica em Administração. Shah e Corley (2006) destacam a importância e a validade da pesquisa de abordagem qualitativa, assim, demonstrando que acreditam no seu crescimento e na sua aceitação em virtude da sua consistência cada vez mais evidente e do rigor científico das técnicas utilizadas. Mozzato e Grzybovski (20II) afirmam que esses modelos de análise de dados são os mais utilizados em estudos organizacionais de abordagem predominantemente qualitativa.

É importante salientar que há uma lacuna no que se refere a trabalhos que tenham como objetivo diferenciar conceitual e metodologicamente os modelos de interpretação de textos, tal como se propõe neste estudo. Para Mozzato e Grzybovski (20II), o conhecimento desses modelos torna-se indispensável para que o pesquisador tenha condições de realizar a escolha mais adequada ao que se propõe estudar, desse modo, visando ao avanço na temática e, consequentemente, no campo de estudo, isto é, o conhecimento das diferentes técnicas de análise de dados torna-se pertinente para que as escolhas possam ser realizadas de maneira mais apropriada, tanto para a temática em estudo como para os propósitos do pesquisador e, também, para o campo de pesquisa. 


\section{MODELOS DE INTERPRETAÇÃO DE TEXTOS}

\section{Análise de Conteúdo}

No início do século xx, durante 40 anos, a Análise de Conteúdo se desenvolveu nos Estados Unidos. Nesse período, o material analisado era essencialmente jornalístico, estendendo-se ao discurso publicitário e literário, ampliando-se para o conteúdo político ou militar das mensagens (CAREGNATO; MUTTI, 2006; FONSECA JÚNIOR, 2009; CHIZZOTTI, 20IO; BARDIN, 20II). O grande impulso recebido pela Análise de Conteúdo ocorreu durante a Segunda Guerra Mundial, quando $25 \%$ das pesquisas com essa técnica estiveram a serviço do governo americano, projetada com o objetivo de desmascarar periódicos e agências de notícias suspeitos de propaganda subversiva, bem como para monitorar as transmissões radiofônicas internas dos nazistas e seus aliados (KRIPPENDORFF, I990; FONSECA JÚNIOR, 2009; BARDIN, 20II).

Conceitualmente, a Análise de Conteúdo refere-se a uma técnica das ciências humanas e sociais destinada à investigação de fenômenos simbólicos por meio de várias técnicas de pesquisa, ocupando-se basicamente com a análise de mensagens. Na ciência, "é tributária do Positivismo, corrente de pensamento desenvolvida por Augusto Comte, cuja principal característica é a valorização das ciências exatas como paradigma de cientificidade e como referência do espírito humano em seu estágio mais elevado" (FONSECA JÚNIOR, 2009, p. 28I).

Conforme Fonseca Júnior (2009, p. 28I), a postura Positivista se encontra presente nas várias definições de Análise de Conteúdo, entre elas, a clássica definição de Bernard Berelson (1952, p. I8), que a designa como "uma técnica de investigação que, através de uma descrição objetiva, sistemática e quantitativa do conteúdo manifesto das comunicações, tem por finalidade a interpretação destas mesmas comunicações".

Assim, corroborando essa definição clássica, Rocha e Deusdará (2005) afirmam que a Análise de Conteúdo pode ser definida como um conjunto de técnicas de análise das comunicações que aposta no rigor do método como forma de não se perder na heterogeneidade de seu objeto, trata-se da sistematização e da tentativa de conferir maior objetividade a uma atitude 
que conta com exemplos dispersos, mas variados, de pesquisa com textos. Os autores comentam que, neste movimento entre a heterogeneidade do objeto e do rigor metodológico, percebe-se em que modelo de ciência se funda a Análise de Conteúdo: um modelo duro, rígido, de corte positivista e centrado na crença de que a neutralidade do método seria a garantia de obtenção de resultados mais precisos. Essa neutralidade consiste em uma relação de distanciamento entre o pesquisador e seu objeto de análise, mediada por uma abordagem metodológica adequada.

De acordo com Chizzotti (20I0, p. II4), “a Análise de Conteúdo é uma dentre as diferentes formas de interpretar o conteúdo de um texto que se desenvolveu, adotando normas sistemáticas de extrair os significados temáticos ou os significantes lexicais, por meio dos elementos mais simples de um texto". Para o autor, consiste, ainda, em "relacionar a frequência da citação de alguns temas, palavras ou ideias em um texto para medir o peso relativo atribuído a um determinado assunto pelo seu autor” (CHIzzoTTI, 20Io, p.II4).

Para Caregnato e Mutti (2006, p. 682), "a maioria dos autores refere-se à Análise de Conteúdo como sendo uma técnica de pesquisa que trabalha com a palavra, permitindo de forma prática e objetiva produzir inferências do conteúdo da comunicação de um texto replicáveis ao seu contexto social”. Conforme esses autores, "na Análise de Conteúdo o texto é um meio de expressão do sujeito, onde o analista busca categorizar as unidades de texto (palavras ou frases) que se repetem, inferindo uma expressão que as representem" (CAREGNATO; MUTTI, 2006, p. 682).

Em complemento aos autores supracitados, Mozzato e Grzybovski (20II, p. 734) afirmam que "a Análise de Conteúdo é um conjunto de técnicas de análise de comunicações, que tem como objetivo ultrapassar as incertezas e enriquecer a leitura dos dados coletados”. Os autores apontam, ainda, que, na busca pela cientificidade e pela objetividade, a Análise de Conteúdo recorreu, em um primeiro momento, a uma abordagem quantitativa por meio da qual a análise das mensagens se fazia pelo cálculo de frequências. Porém, logo, deu-se lugar à abordagem qualitativa, desse modo, possibilitando que a técnica fosse utilizada em ambas as abordagens, até 
mesmo, concomitantemente. Assim, por mais que tenha, na sua origem, a quantificação, súbito, compreendeu-se que esta técnica poderia ser aplicada, também, na análise qualitativa, pois sua característica é a inferência, isto é, variáveis inferidas a partir de variáveis de inferência no nível da mensagem, quer essas estejam baseadas ou não em indicadores quantitativos.

Portanto, a Análise de Conteúdo é uma técnica que pode ser utilizada tanto na pesquisa quantitativa como na investigação qualitativa, mas com aplicações diferentes (BARDIN, 20II). Silva et al. (2005) e Caregnato e Mutti (2006) diferenciam essas duas abordagens ao referir que na quantitativa se traça uma frequência das características que se repetem no conteúdo do texto, enquanto que na qualitativa se considera a presença ou a ausência de uma dada característica num determinado fragmento de mensagem.

Embora seja considerada uma técnica híbrida por relacionar o formalismo estatístico e a análise qualitativa de materiais, a Análise de Conteúdo oscila entre os dois polos, ora valorizando o aspecto quantitativo, ora o qualitativo, dependendo da ideologia e dos interesses do pesquisador. Contudo, apesar da introdução da inferência, a empatia pelos números não desapareceu (FONSECA JúNIOR, 2009).

Com destaque para a natureza quantitativa da Análise de Conteúdo, Chizzotti (20I0, p. II4) afirma que se trata de "um tipo de análise da comunicação que pretende garantir a imparcialidade objetiva, socorrendose da quantificação das unidades do texto claramente definidas, para gerar resultados quantificáveis ou estabelecer a frequência estatística das unidades de significado". O autor destace que se parte do pressuposto que um texto contém sentidos e significados que podem ser aprendidos por um leitor que interpreta a mensagem contida nele por meio de técnicas sistemáticas apropriadas. A mensagem pode ser aprendida decompondo-se o conteúdo do texto em fragmentos mais simples, tais como palavras, termos ou frases significativas de uma mensagem.

Por mais que muitos autores abordem a Análise de Conteúdo utilizando conceitos por vezes diferenciados, a definição que norteia este ensaio teórico é a de Bardin (20II, p. 48), que estabelece a Análise de Conteúdo como:

Um conjunto de técnicas das comunicações, visando obter por procedimentos sistemáticos e objetivos de descrição do conteúdo das mensagens indicadores 
(quantitativos ou não) que permitam a inferência de conhecimentos relativos às condições de recepção/produção (variáveis inferidas) dessas mensagens.

A autora ainda explica que:

Pertencem ao domínio da Análise de Conteúdo todas as iniciativas que, a partir de um conjunto de técnicas parciais mas complementares, consistam na explicitação e sistematização do conteúdo das mensagens e da expressão deste conteúdo, com o contributo de índices passíveis ou não de quantificação, a partir de um conjunto de técnicas, que, embora parciais, são complementares (BARDIN, 2OII, p. 48).

Durante algum tempo, a Análise de Conteúdo foi considerada quase sinônimo de análise de mensagens escritas e impressas, ao ponto de até as mensagens orais serem analisadas sob a forma de transcrições. Atualmente, apenas a análise de materiais impressos se encontra normalmente desenvolvida; em segundo plano, ficam os estudos de mensagens sonoras e audiovisuais; em último plano, encontram-se as mensagens dos outros canais sensoriais, muito pouco estudados (FONSECA JúNIOR, 2009). Nesse sentido, Flick (2009, p. 29I) aponta que "a Análise de Conteúdo é um dos procedimentos clássicos para analisar o material textual, não importando qual a origem desse material”.

Assim, a Análise de Conteúdo trabalha tradicionalmente com materiais textuais escritos, sejam eles produzidos em pesquisa, a partir, por exemplo, das transcrições de entrevista e dos protocolos de observação; ou já existentes, produzidos para outros fins, como textos de jornais (CAREGNATO; MUTTI, 2006).

Krippendorff (1990) cita três características fundamentais da Análise de Conteúdo: orientação fundamentalmente empírica, exploratória, vinculada a fenômenos reais e de finalidade preditiva; transcendência das noções normais de conteúdo, envolvendo as ideias de mensagem, canal, comunicação e sistema; metodologia própria, que permite ao investigador programar, comunicar e avaliar um projeto de pesquisa com independência de resultados.

Flick (2009) destaca que uma das características essenciais da Análise de Conteúdo é a utilização de categorias, comumente, obtidas de modelos teóricos. As categorias são levadas para o material empírico, e não necessariamente desenvolvidas a partir desse, conquanto sejam 
reiteradamente avaliadas em contraposição a esse material e, se necessário, modificadas. Segundo o autor, o objetivo principal na Análise de Conteúdo é reduzir o material empírico.

O procedimento descrito por Flick (2009) consiste na técnica de Análise de Conteúdo mais generalizada, transmitida e antiga, denominada de análise categorial, que considera a totalidade de um texto, passando-o pelo crivo de classificação e do recenseamento, segundo a frequência de presença ou de ausência de itens de sentido (CAREGNATO; MUTTI, 2006; BARDIN, 20II).

$\mathrm{Na}$ verdade, a Análise de Conteúdo construiu um conjunto de procedimentos e técnicas para extrair o sentido de um texto por meio de unidades elementares: palavras-chave, léxicos, categorias e temas, desse modo, procurando identificar a frequência ou a constância dessas unidades para fazer inferências e extrair os significados contidos no texto a partir de indicadores objetivos (CHIzzotTI, 20Io). Segundo Bardin (20II, p. 37), "não se trata de um instrumento, mas de um leque de apetrechos; ou, com mais rigor, será um único instrumento, mas marcado por uma grande disparidade de formas e adaptável a um campo de aplicação muito vasto: as comunicações".

No Quadro I são apresentadas e descritas as principais técnicas utilizadas na Análise de Conteúdo, segundo Fonseca Júnior (2009) e Bardin (20II):

Quadro I Técnicas utilizadas na Análise de Conteúdo

\begin{tabular}{|c|c|}
\hline Técnica & Descrição \\
\hline $\begin{array}{l}\text { Análise } \\
\text { Categorial }\end{array}$ & $\begin{array}{l}\text { - Funciona por operações de desmembramento do texto em unidades, em categorias } \\
\text { segundo reagrupamentos analógicos. Entre as possibilidades de categorização, } \\
\text { encontra-se a investigação dos temas ou a análise temática (BARDIN, 2011). }\end{array}$ \\
\hline $\begin{array}{l}\text { Análise de } \\
\text { Avaliação } \\
\text { ou Análise } \\
\text { de Asserção } \\
\text { Avaliativa }\end{array}$ & $\begin{array}{l}\text { - Sua finalidade é medir as atitudes do locutor quanto aos objetivos do que se fala. } \\
\text { Parte do princípio de que a linguagem representa e reflete diretamente aquele que } \\
\text { a utiliza. Por conseguinte, podemos nos contentar com os indicadores manifestos, } \\
\text { explicitamente contidos na comunicação, para fazer inferências a respeito da fonte } \\
\text { de emissão (BARDIN, 2011). }\end{array}$ \\
\hline $\begin{array}{l}\text { Análise de } \\
\text { Enunciação }\end{array}$ & $\begin{array}{l}\text { - Sua principal característica é se apoiar numa concepção de discurso como palavra } \\
\text { em ato, considera a produção da palavra como um processo. Parte do princípio de } \\
\text { que o discurso não é um produto acabado, mas um momento num processo de } \\
\text { elaboração (BARDIN, 2011). }\end{array}$ \\
\hline
\end{tabular}




\begin{tabular}{|c|c|}
\hline Técnica & Descrição \\
\hline $\begin{array}{l}\text { Análise } \\
\text { Proposicional do } \\
\text { Discurso (APD) }\end{array}$ & $\begin{array}{l}\text { - Considerada uma variante da análise temática, que procura resolver algumas } \\
\text { insuficiências da divisão em categorias. Seu objetivo é identificar o universo } \\
\text { de referências dos agentes sociais, ou seja, como e por meio de que estrutura } \\
\text { argumentativa se exprimem as questões e as ações dos agentes (BARDIN, 2011). }\end{array}$ \\
\hline $\begin{array}{l}\text { Análise da } \\
\text { Expressão }\end{array}$ & $\begin{array}{l}\text { - Parte do princípio de que existe uma correspondência entre o tipo de discurso e } \\
\text { as características do locutor e seu meio. Considera que os traços pessoais, o estado } \\
\text { do locutor ou sua reação a uma situação modificam o discurso tanto na sua forma } \\
\text { como no seu conteúdo (FONSECA JÚNIOR, 2009). } \\
\text { - Prima pelo formal e não pelo semântico, isto é, os indicadores utilizados não são de } \\
\text { ordem semântica (conteúdo plano dos significados), mas de ordem formal (plano } \\
\text { dos significantes e da sua organização) (BARDIN, 2011). }\end{array}$ \\
\hline $\begin{array}{l}\text { Análise da } \\
\text { Contingência } \\
\text { ou Análise } \\
\text { Associativa } \\
\text { ou Análise da } \\
\text { Coocorrência }\end{array}$ & $\begin{array}{l}\text { - Considera que o mais importante não é o número de vezes em que certas palavras, } \\
\text { temas ou tipos de personagens aparecem numa mensagem, mas sim como eles } \\
\text { estão organizados entre si, ou seja, o que está associado a que (FONSECA JÚNIOR, } \\
\text { 2009). } \\
\text { - Procura extrair do texto as relações entre os elementos da mensagem ou, mais } \\
\text { exatamente, dedica-se a assinalar as presenças simultâneas (coocorrência ou } \\
\text { relação de associação) de dois ou mais elementos na mesma unidade de contexto, } \\
\text { isto é, num fragmento de mensagem previamente definido (BARDIN, 2011). }\end{array}$ \\
\hline Análise Estrutural & $\begin{array}{l}\text { - Parte do pressuposto de que todo texto é uma realidade estruturada, que não } \\
\text { se revela pelo conteúdo manifesto, pois se encontra implícita (FONSECA JÚNIOR, } \\
\text { 2009). } \\
\text { - Engloba um número de técnicas que tentam passar do nível atômico da análise a } \\
\text { um nível molecular, e centram os seus procedimentos, mesmo num plano muito } \\
\text { elementar, mais nos laços que unem as componentes do discurso do que nos } \\
\text { próprios componentes (BARDIN, 2011). }\end{array}$ \\
\hline $\begin{array}{l}\text { Análise do } \\
\text { Discurso }\end{array}$ & $\begin{array}{l}\text { - Procura estabelecer ligações entre as condições de produção do discurso e sua } \\
\text { estrutura. Considera que um discurso é determinado pelas suas condições de } \\
\text { produção e por um sistema linguístico (FONSECA JÚNIOR, 2009). } \\
\text { - As raízes da Análise do Discurso são diversas, heterogêneas, e vários campos de } \\
\text { pesquisas e práticas se desenvolvem independentemente e continuam a coexistir, } \\
\text { sem relação entre si (BARDIN, 2011). }\end{array}$ \\
\hline
\end{tabular}

Quanto à Análise do Discurso, elencada como uma das técnicas, Fonseca Júnior (2009) observa que há uma estreita ligação entre ela e a Análise de Conteúdo. Bardin (20II) enquadra a Análise do Discurso como pertencente ao campo da Análise de Conteúdo, salientando que há limitações inerentes àquela. Com a finalidade de identificar aspectos que diferenciem estas duas técnicas de análise, no tópico subsequente, serão abordados os conceitos teórico-metodológicos sobre a Análise do Discurso enquanto modelo de interpretação de textos. 


\section{ANÁLISE DO DISCURSO}

O surgimento da Análise do Discurso se deu no fim dos anos de 1960, em decorrência de insuficiências de uma análise de texto que se vinha praticando e que se pautava mormente por uma visão "conteudista", característica central das práticas dos estudos em Análise de Conteúdo, discutido no tópico anterior. A Análise do Discurso propõe o entendimento de um plano discursivo que articula linguagem e sociedade, estas intercaladas pelo contexto ideológico. Seu objetivo não é instituir uma "nova linguística", mas consolidar uma alternativa de análise, mesmo que marginal, à perspectiva tradicional (ROCHA; DEUSDARÁ, 2005).

Sob esse ponto de vista, Fagundes e Nogueira (2008) concordam com os autores supracitados ao afirmar que a Análise do Discurso decorre de uma nova percepção da função da linguagem, que não se limita a ser um suporte do pensamento ou um instrumento de comunicação, mas apreendida como interação e uma construção social, ampliando-se, portanto, o enfoque da linguística. Nessa perspectiva, evidencia-se que uma linguística que se limite ao estudo interno da língua não poderá dar conta do seu objeto, é necessário que ela traga para o interior do seu sistema um enfoque que articule o linguístico e o social (BRANDÃO, 2004).

Segundo seus precursores, a Análise do Discurso pretende contribuir com as hermenêuticas contemporâneas, que, ao analisarem os discursos, apontam que estes contêm um sentido oculto que deve ser captado e o qual, sem uma técnica adequada, permanece obscuro e inatingível (MAINGUENEAU, I997; FAGUNDES; NOGUEIRA, 2008).

Portanto, a Análise do Discurso trabalha com o sentido e não com o conteúdo do texto, um sentido que não é traduzido, mas produzido. A Análise do Discurso tem a pretensão de interrogar os sentidos estabelecidos em diversas formas de produção, verbais ou não verbais, bastando que sua materialidade produza sentidos para interpretação (CAREgnato; MUTTI, 2006). Pressupõe-se, assim, que o discurso não se restringe a uma estrutura ordenada de palavras, nem a uma descrição ou a um meio de comunicação, tampouco se reduz a mera expressão verbal do mundo (CHIzzotTi, 20I0). 
Mozzato e Grzybovski (20II, p. 737-738) colaboram com os autores supracitados ao aduzirem que:

A Análise do Discurso consiste numa técnica de análise que explora as relações entre discurso e realidade, verificando como os textos são feitos, carregando significados por meio dos processos sociais. Os textos podem ser considerados tanto uma unidade discursiva como manifestação material do próprio discurso.

Aborda-se a Análise do Discurso ora como uma disciplina interdisciplinar, ora como uma perspectiva teórico-metodológica ou, ainda, como uma técnica para análise de discursos (FAGUNDES; NOGUEIRA, 2008). Segundo Caregnato e Mutti (2006), a Análise do Discurso não é uma metodologia, é uma disciplina de interpretação estabelecida pela intersecção de epistemologias distintas, pertencentes a áreas da linguística, do materialismo histórico e da psicanálise. Da linguística, absorveu a noção de fala para discurso; do materialismo histórico, emergiu a teoria da ideologia; e, da psicanálise, veio a noção de inconsciente.

A Análise do Discurso envolve um amplo e heterogêneo conjunto de teorias e práticas que corresponde a objetivos e finalidades diversos e nutre uma diversidade de orientações de pesquisa e disciplinas (CHIzzotTI, 20Iо; BARDIN, 20II). Esta técnica de análise de dados tem como objetivo analisar o uso da linguagem em discursos contextualizados de pessoas que interagem, como também os processos pelos quais dão forma linguística e produzem sentido nas suas interações sociais (CHIzzotTI, 20I0).

Não existe apenas uma linha de Análise do Discurso, existem muitos estilos diferentes, com enfoques variados, a partir de diversas tradições teóricas, porém todas reivindicando o mesmo nome. O que esses diferentes estilos parecem ter em comum, ao tomar o discurso como objeto, é que compartilham de uma rejeição da noção de que a linguagem é simplesmente um meio neutro de refletir, ou descrever o mundo, e uma convicção da importância central do discurso na construção da vida social (CAREGNATO; MUTTI, 2006).

Para Flick (2009), a Análise do Discurso foi desenvolvida a partir de diferentes panos de fundo, sendo um deles a Análise de Conversação, técnica que será abordada no tópico subsequente deste estudo, e outro seria o Construcionismo Social. 
Nesse sentido, no Quadro 2, são apresentadas e descritas as principais perspectivas da Análise do Discurso, segundo Chizzotti (2010):

\section{Quadro 2 Perspectivas da Análise do Discurso}

$\begin{array}{ll}\text { Perspectiva } & \text { Descrição } \\ \text { Estruturalismo } & \text { - O estruturalismo é tributário das ideias de Saussure (1970), que estudou a linguagem } \\ & \text { como a faculdade universal de falar, distinguindo a língua (sistema de sinais que } \\ & \text { se usa para se comunicar) e a fala (uso concreto e individual dos elementos, sujeito } \\ & \text { a variações). } \\ \text { - Para o estruturalismo linguístico, a língua é um sistema estrutural de relações } \\ \text { opostas ou equivalentes, entre os diversos elementos que determinam o significado, } \\ \text { este deriva das relações variáveis entre os diversos elementos, e não da referência } \\ \text { a um objeto específico; os vários elementos do texto podem ser analiticamente } \\ \text { extraídos, arranjados, combinados ou transformados para criar um novo sentido. } \\ \text { - Os estruturalistas tinham a expectativa de criar uma ciência objetiva que buscasse } \\ \text { as relações descritivas ou causais de uma estrutura linguística ou da estrutura social. }\end{array}$

Análise $\quad$-O papel da Análise Foucaultiana do Discurso é um desenlear das relações de poder Foucaultiana do ocultas nos aprimoramentos epistemológicos, no discurso tido como objetivo, nos Discurso conceitos formais.

- Na perspectiva foucaultiana, todo discurso, suas definições, seus conceitos e suas transformações semânticas revelam a tensão entre indivíduos, o contexto histórico e social, o poder e a resistência nas inter-relações humanas.

- O discurso é um meio de produzir e organizar o significado no contexto social. A linguagem é a matriz dos discursos que se constituem em formações discursivas: modos significativos de organizar as experiências humanas do mundo social em linguagem e, assim, constituir modos de conhecimento.

Análise $\quad$ A semiótica é uma teoria dos signos que analisa os modos de produção, Semiótica do funcionamento e recepção dos diferentes sistemas de signos simbólicos que Discurso permitem a comunicação entre indivíduos e grupos.

- Embora derivada da linguagem, a semiótica visa a uma análise sistemática dos sistemas simbólicos, dentre os quais a linguagem, para revelar a relação entre o significante ou expressão, tal como a palavra ou o símbolo, e o significado ou o conteúdo.

- A Análise Semiótica do Discurso busca decodificar o sistema de signos situado no texto, assim, estabelecendo as articulações homólogas, analógicas e simbólicas dos signos a fim de mostrar as conexões e o sistema de signos que dão significado à realidade.

Análise Crítica - Deriva originalmente do grupo de intelectuais da Escola de Frankfurt, onde foi do Discurso empreendida uma crítica às instituições políticas e sociais que historicamente oprimem as pessoas a fim de expor as formas culturais de opressão e oferecer os instrumentos para superá-las.

- A pesquisa crítica possui alguns referenciais que podem ser condensados nas seguintes proposições: todo pensamento é fundamentalmente mediado por relações de poder; os fatos nunca estão isolados do domínio dos valores ou separados de alguma forma de inscrição ideológica; a relação entre o conceito e o objeto, entre o significante e o significado nunca é estável ou fixa; a linguagem é central na formação da subjetividade, seja consciente ou inconscientemente; certos grupos são privilegiados em relação a outros.

- A tarefa da Análise Crítica do Discurso é considerar a linguagem conexa com a estrutura social, avaliar a função do discurso, sua ideologia na produção, na manutenção e na transformação das relações sociais de poder, desmistificar os discursos dominantes e construir uma consciência crítica. 
Manhães (2009) trabalha com duas abordagens em Análise do Discurso: a Análise do Discurso Francesa e a Análise do Discurso Inglesa ou AngloSaxônica. Segundo o autor, a primeira caracteriza-se pela ênfase no "assujeitamento" do emissor, que se expressa mediante a incorporação de discursos sociais já instituídos: religioso, científico, filosófico, mitológico, poético, jornalístico, publicitário, corporativo, etc. A segunda se caracteriza pelo papel ativo do sujeito, aquele que utiliza pragmaticamente as palavras para fazer coisas, embora não descarte o fato de o sujeito estar obrigado a obedecer aos imperativos linguísticos, o que implica em um relativo assujeitamento.

O Quadro 3 resume as diferenças entre essas abordagens, segundo Maingueneau (1997):

Quadro 3 Análise do Discurso Francesa versus Análise do Discurso Inglesa

\begin{tabular}{|lll|}
\hline & Análise de Discurso Francesa & $\begin{array}{l}\text { Análise de Discurso Anglo- } \\
\text { Saxônica }\end{array}$ \\
\hline Tipo de Discurso & $\begin{array}{l}\text { Escrito } \\
\text { Quadro institucional doutrinário }\end{array}$ & $\begin{array}{l}\text { Oral } \\
\text { Conversação cotidiana comum }\end{array}$ \\
\hline $\begin{array}{l}\text { Objetivos } \\
\text { determinados }\end{array}$ & $\begin{array}{l}\text { Propósitos textuais = explicação e forma } \\
\text { Construção do objeto }\end{array}$ & $\begin{array}{l}\text { Propósitos comunicativos = } \\
\text { descrição e uso } \\
\text { Imanência do objeto }\end{array}$ \\
\hline Método & Estruturalismo (linguística e história) & $\begin{array}{l}\text { Interacionismo (psicologia e } \\
\text { sociologia) }\end{array}$ \\
\hline Origem & Linguística & \begin{tabular}{l} 
Antropologia \\
\hline
\end{tabular}
\end{tabular}

Fonte: Adaptado de Maingueneau (1997)

Bardin (20II, p. 276) explica que:

A corrente anglo-saxônica designa por discurso qualquer forma de interação formal ou informal, qualquer linguagem no seu contexto social e cognitivo, e inspira-se na psicologia, na antropologia, na pragmática e na etnometodologia, a qual observa o modo como a linguagem é utilizada em situações de vida corrente.

Enquanto que, na corrente francesa, a Análise do Discurso advém do estruturalismo e da linguística e está dividida entre a descrição linguística e a 
dificuldade em responder às exigências interpretativas das ciências humanas.

\section{ANÁLISE DE CONVERSAÇÃO}

A Análise de Conversação, ou, como vem sendo chamada, os estudos da fala-em-interação, surgiu, na década de 1960, na linha da Etnometodologia e da Antropologia Cognitiva, e preocupou-se, até meados dos anos de 1970, sobretudo com a descrição das estruturas da conversação e seus mecanismos organizadores (MARCUSCHI, 2003; BINET, 20I0). A Etnometodologia trata da constituição da realidade no mundo do dia a dia e investiga a forma das pessoas se apropriarem do conhecimento social e das ações (etno); diz respeito, ainda, à forma metódica de como os membros de uma sociedade aplicam seu saber sociocultural (metodologia) (MARCUSCHI, 2003).

Assim, este modelo de análise partiu, inicialmente, do princípio básico de que todos os aspectos da ação e da interação social poderiam ser examinados e descritos em termos de organização estrutural convencionalizada ou institucionalizada, explicando a sua predominância nos estudos organizacionais de conversação (MARCUSCHI, 2003).

Sobre o seu contexto atual, o autor supracitado afirma que a Análise de Conversação se preocupa com a especificação dos conhecimentos linguísticos, paralinguísticos e socioculturais que devem ser partilhados para que a interação seja bem-sucedida; a análise de estruturas foi ultrapassada e atingiu-se os processos cooperativos presentes na atividade conversacional, o problema passou da organização para a interpretação. Para o autor, a Análise de Conversação procede pela indução e parte de dados empíricos em situações reais, o que lhe dá uma vocação naturalística com poucas análises quantitativas e prevalência das descrições e interpretações qualitativas.

Nesse sentido, Silva et al. (2009, p. 4) inferem que:

Um pressuposto importante para se realizar pesquisas numa perspectiva de Análise de Conversação é analisar interações naturalísticas. A palavra naturalística indica que os dados não são experimentais ou gerados a partir de um roteiro prévio, mas que foram coletados no ambiente em que eles aconteceram.

Logo, os dados não provêm de coletas realizadas por meio de entrevistas preconcebidas, questionários ou experimentos com intervenções, a Análise 
de Conversação gira em torno da investigação de fatos e situações que ocorrem no dia a dia e da maneira como acontecem, mesmo que não haja pesquisa sendo realizada (PASSUELLO; OSTERMANN, 2007; FLICK, 2009; SILVA et al., 2009).

Borges e Gonçalo (20Io, p. I), em consonância com os autores supracitados, definem a Análise de Conversação como "uma análise sistemática da conversa produzida em situações diárias da interação humana, denominada de fala-em-interação (talk-in-interaction), que ocorrem naturalmente, sem a interferência do pesquisador". Desse interesse pelas situações e ações sociais que ocorrem no dia a dia é que emana o seu enquadramento na linha da Etnometodologia.

Marcuschi (2003) afirma que a Análise de Conversação é uma tentativa de responder a questões do tipo: como é que as pessoas se entendem ao conversar?; como sabem que estão se entendendo?; como sabem que estão agindo coordenada e cooperativamente?; como usam seus conhecimentos linguísticos e outros para criar condições adequadas à compreensão mútua?; como criam, desenvolvem e resolvem conflitos interacionais?

Nessa perspectiva, estuda-se a fala das pessoas propriamente dita, e não seus pensamentos, emoções, atitudes, crenças ou experiências de vida, que são assumidos como subjacentes à fala (e que podem ser expressos por meio dela). Trata da fala como uma forma de ação social, ou seja, como uma forma de fazer coisas no mundo (discordar, reclamar, etc.). Assim, investigase como as pessoas envolvidas em uma interação social compreendem o que sua fala está fazendo (PASSUELlo; OSTERMANN, 2007).

As Análises de Conversação são eminentemente descritivas da fala dos participantes, estes, por sua vez, constroem uma realidade social nas comunicações interpessoais, por meio de interações sociais, em que se mostram capazes de falar, silenciar, interromper, ocultar, produzir uma imagem de si e provocar a exposição do outro (CHIzzotTI, 20Io).

Portanto, o foco da Análise de Conversação não é o significado subjetivo para os participantes, mas a forma como essa interação é organizada. O tópico de pesquisa é o estudo da vida cotidiana, por isso é crucial o papel do contexto em que as interações ocorrem. Cada evento de fala em interação 
apresenta esforços de produção dos membros ali mesmo, ou seja, das contribuições conversacionais dos membros (BORGES; GONÇALO, 20IO).

Em virtude da vocação naturalística da Análise de Conversação, a principal maneira de se obter os chamados dados naturalísticos é gravando as conversas dos participantes em áudio e/ou em vídeo e, consequentemente, um procedimento imprescindível em pesquisas que se utilizam da Análise de Conversação é a transcrição das conversas gravadas. A transcrição dos dados não é um mero procedimento que transforma texto oral em documento escrito, visto que ela obedece a uma série de convenções que sinalizam os diferentes aspectos que permearam uma determinada conversa, tais como pausa, sobreposição de falas, entonação ascendente ou descendente, falas coladas (quando um participante começa a falar imediatamente após outro ter cessado sua fala), palavras proferidas de forma incompleta, aspiração ou expiração de ar durante a fala, entre outros que se mostrarem relevantes (sILVA et al., 2009).

Assim, os analistas da conversação privilegiam como base empírica dos estudos da linguagem as gravações e as transcrições integrais de trocas conversacionais ocorridas em quadros naturais, isto é, não provocadas ou modificadas pelos investigadores. O valor semântico de uma forma linguística (um "sim", por exemplo) é inseparável da sequência conversacional, só um registro completo da interação verbal, fiel à sua organização sequencial, permite ser analisado adequadamente (BINET, 20IO).

Marcuschi (2003) explica que a Análise de Conversação se dá com base em material empírico reproduzindo conversações reais e considera detalhes não apenas verbais, mas entonacionais, paralinguísticos e outros, logo, algumas informações adicionais devem aparecer na transcrição, uma vez constatada sua relevância.

Passuello e Ostermann (2007) justificam a importância das interações analisadas, a partir dessa perspectiva, serem, necessariamente, gravadas em áudio: diferentemente de pesquisas que se centram no conteúdo das falas ou apenas no que foi dito, estudos de Análise de Conversação atentam primordialmente para o como as coisas foram ditas. Em análises linguísticas e interacionais, não se pode confiar apenas em anotações e memória 
para lembrança de detalhes ocorridos nos turnos de fala (pausas, falas simultâneas, hesitações e outros fenômenos interacionais). É somente com dados gravados em áudio e/ ou em vídeo que analistas da conversa podem estudar os detalhes das reais interações.

Para Flick (2009), inicialmente, a Análise de Conversação se limitou à conversação em sentido estrito, ou seja, conversas telefônicas, conversas em família, nas quais não existe nenhuma distribuição de papéis específicos. No entanto, atualmente, ela se ocupa cada vez mais com essa distribuição específica de papéis e de assimetrias, como a conversa de aconselhamento, interações judiciais, ou seja, conversações que ocorram em contextos institucionais específicos.

As situações em que ocorrem as assimetrias ou os diálogos assimétricos se caracterizam, segundo Marcuschi (2003), por conversações em que um dos seus participantes tem o direito de iniciar, orientar, dirigir e concluir uma interação e exercer pressão sobre o outro participante, como, por exemplo, nas entrevistas, nos inquéritos, nas interações em sala de aula, etc. Enquanto que, nas situações de simetria ou diálogos simétricos, os vários participantes têm supostamente o mesmo direito à autoescolha da palavra e do tema a tratar-se. O autor indica que, na segunda situação, tem-se propriamente uma conversação em sentido estrito.

Um dos aspectos fundamentais para compreender os estudos de Análise de Conversação é o da sequencialidade, isto é, quando uma pessoa fala, ela está levando em consideração o que foi dito anteriormente por outra pessoa. Intrínsecas a este aspecto, estão as ideias de que os participantes estão sempre evidenciando uns para os outros a inteligibilidade da interação; o que se diz a cada turno tem uma configuração sequencial e não são elementos isolados que têm o mesmo valor e realizam as mesmas ações onde quer que sejam produzidos; os participantes alternam-se nos papéis de falante e ouvinte (silva et al., 2009).

Flick (2009) destaca alguns fatores que devem ser observados na Análise de Conversação: pressupõe que a interação prossiga de uma forma ordenada e que nada nela deva ser considerado aleatório; o contexto da interação não apenas a influencia, mas é nela produzido e reproduzido; a decisão quanto 
ao que é relevante na interação social e para a interpretação apenas pode ser tomada por meio da própria interpretação.

Por fim, Marcuschi (2003) define cinco características básicas constitutivas da Análise de Conversação: interação entre pelo menos dois falantes; ocorrência de pelo menos uma troca de falantes; presença de uma sequência de ações coordenadas; execução em uma identidade temporal; envolvimento em uma interação centrada.

Quanto à natureza indutiva e descritiva da Análise de Conversação, Binet (2010) conclui que esta técnica e o seu sistema articulado de conceitos são dotados de um poder descritivo e analítico que habilita o investigador a estudar minuciosa e intensivamente um dado evento interacional encarado na sua singularidade. O seu interesse em descrições densas de práticas e comportamentos constitui chaves para uma compreensão de dentro (intracultural) das culturas humanas consideradas na sua diversidade. Para o autor, em vez de projetar de cima para baixo conceitos rígidos, os analistas da conversação chamam atenção para a riqueza das reformulações conceituais e das descobertas proporcionadas por uma abordagem verdadeiramente indutiva atenta às singularidades de cada interação verbal transcrita.

Após essa breve discussão sobre os conceitos teórico-metodológicos de Análise de Conteúdo, Análise do Discurso e Análise de Conversação, na seção subsequente serão discutidas algumas diferenças perceptíveis entre esses modelos de interpretação de textos à luz dos achados na literatura especializada.

\section{DIFERENÇAS ENTRE OS MODELOS DE INTERPRETAÇÃO DE TEXTOS}

Inicialmente, é importante destacar que, segundo Flick (2009), os três modelos de interpretação de textos discutidos neste ensaio teórico podem ser classificados em duas categorias de estratégias de tratamento dos textos. A Análise de Conteúdo faz parte da categoria de estratégia que adota o procedimento de codificar um determinado material empírico, com o objetivo de categorizar ou desenvolver uma teoria. Enquanto que a Análise do Discurso e a Análise de Conversação seguem a estratégia de analisar sequencialmente um determinado texto, buscando a reconstrução da sua 
estrutura. Assim, verifica-se uma primeira diferença entre esses modelos, a Análise de Conteúdo busca reduzir o material empírico, isto é, o texto a ser interpretado. Já a utilização da Análise do Discurso e da Análise de Conversação acarretará um aumento do material textual.

Uma segunda diferença perceptível está no tipo de abordagem das técnicas. A interpretação da Análise de Conteúdo poderá ser tanto quantitativa quanto qualitativa (SILVA et al., 2005; CAREGNATO; MUTTI, 2006; FONSECA JÚNIOR, 2009; BARDIN, 20II; MOZZATO, GRZYBOvski, 20II). Na Análise do Discurso, a interpretação é apenas qualitativa (CAREGNATO; MUTTI, 2006). E, na Análise de Conversação, há a prevalência das interpretações qualitativas, com poucas análises quantitativas (MARCUSCHI, 2003).

Com relação à postura teórica, a Análise de Conteúdo possui um corte positivista, aposta no rigor, na sistematização e na objetividade da técnica (ROCHA; DEUSDARÁ, 2005; FONSECA JÚNIOR, 2009). A Análise de Conversação segue a linha da Etnometodologia e da Antropologia Cognitiva (MARCUSCHI, 2003; BINET, 20IO). Já a Análise do Discurso envolve um amplo e heterogêneo conjunto de teorias (CAREGNATO; MUTTI, 2006; CHIZZOTTI, 20IO; BARDIN, 20II), contudo, Flick (2009) aponta como um dos panos de fundo desta técnica o Construcionismo Social.

Na sequência, as diferenças teórico-metodológicas serão discutidas por meio de uma confrontação aos pares: Análise de Conteúdo versus Análise do Discurso; Análise de Conteúdo versus Análise de Conversação; Análise do Discurso versus Análise de Conversação.

\section{Análise de Conteúdo versus Análise do Discurso}

ao compararem-se os achados na literatura que abordam estes dois modelos, verifica-se que a análise de conteúdo se ocupa basicamente com a análise de mensagens (SIMÃO; GOBBI; SIMÃO, 2005; FONSECA JÚNIOR, 2009; CHIZZOTTI, 20IO; BARDIN, 20II; MOZZATO, GRZYBOVSKI, 20II), o mesmo ocorre com a análise do discurso. uma importante diferença entre esses modelos é que apenas a análise de conteúdo cumpre com o requisito de sistematização (FONSECA JúNIOR, 2009).

Contudo, a principal diferença entre a Análise de Conteúdo e a Análise do Discurso é o modo de acesso ao objeto (CAREGNATO; MUTTI, 2006). A Análise do 
Discurso trabalha com o sentido (MAINGUENEAU, I997; CAREGNATO; MUTTI, 2006; FAGUNDES; NOGUEIRA, 2008); já a Análise de Conteúdo trabalha com o conteúdo, assim, estabelecendo categorias para sua interpretação (ROCHA; DEUSDARÁ, 2005; CAREGNATO; MUTTI, 2006; FLICK, 2009; CHIZZOTTI, 20IO; BARDIN, 20II).

A Análise do Discurso busca os efeitos de sentido relacionados ao discurso e preocupa-se em compreender os sentidos que o sujeito manifesta por meio dele. Enquanto que a Análise de Conteúdo se fixa, principalmente, no conteúdo do texto, sem fazer relações além deste, e espera compreender o pensamento do sujeito mediante o conteúdo expresso no texto, numa concepção transparente de linguagem (CAREGNATO; MUTTI, 2006). Contudo, Bardin (20II) destaca que a Análise de Conteúdo também deve levar em consideração o que não está explicitamente presente no texto.

A Análise de Conteúdo centra-se na crença de que a neutralidade da técnica, ou seja, uma relação de distanciamento entre o pesquisador e seu objeto de análise, seria a garantia de obtenção de resultados mais precisos (ROCHA; DEUSDARÁ, 2005). De modo oposto, a Análise do Discurso rejeita a noção de que a linguagem é simplesmente um meio neutro de refletir (CAREGNATO; MUTTI, 2006).

\section{ANÁLISE DE CONTEÚDO VERSUS ANÁLISE DE CONVERSAÇÃO}

O ponto de diferenciação entre a Análise de Conteúdo e a Análise de Conversação está na questão das interações naturalísticas. A Análise de Conteúdo trabalha tradicionalmente com materiais textuais escritos, sejam eles produzidos em pesquisa, a partir, por exemplo, das transcrições de entrevista e dos protocolos de observação; ou já existentes, produzidos para outros fins (CAREgnato; mutTI, 2006). E a Análise de Conversação, em virtude de sua vocação naturalística, gira em torno da investigação de fatos e situações que ocorrem no dia a dia e da maneira como acontecem, ou seja, não provocados ou modificados pelos pesquisadores, os dados não provêm de coletas realizadas por meio de entrevistas, questionários ou experimentos com intervenções (MARCUSCHI, 2003; PASSUELLO; OSTERMANN, 2007; FLICK, 2009; SILVA et al., 2009; BINET, 20IO; BORGES; GONÇALO, 20IO). 


\section{ANÁLISE DO DISCURSO VERSUS ANÁLISE DE CONVERSAÇÃO}

Embora a Análise do Discurso tenha se desenvolvido tendo como um dos panos de fundo a Análise de Conversação, o seu foco empírico concentra-se mais no conteúdo da fala, em seu assunto e sua organização mais social do que propriamente linguística (FLICK, 2009). Isto é, combina procedimentos analíticos de linguagem com análises de processos e construções, sem se restringir aos aspectos formais dos processos linguísticos. Já a Análise de Conversação estuda a fala das pessoas propriamente dita, atenta-se, primordialmente, para o como as coisas são faladas (PASSUELLO; OSTERMANN, 2007; CHIZZOTTI, 20I0).

A Análise de Conversação busca investigar fatos e situações da vida cotidiana (MARCusChI, 2003; PASSUello; OSTERMANN, 2007; FLICK, 2009; SILVA et al., 2009; BINET, 20IO; BORGES; GONÇALO, 20IO). Enquanto que os procedimentos da Análise do Discurso referem-se não apenas às conversas cotidianas, mas, também, a outros tipos de dados gerados de, por exemplo, roteiros de entrevistas preconcebidos (FLICK, 2009). 


\section{CONSIDERAÇÕES FINAIS}

O presente estudo se propôs a discutir teoricamente sobre três dos modelos de interpretação de textos mais utilizados em pesquisas de abordagem qualitativa, bem como apresentar, preliminarmente, diferenças perceptíveis entre eles.

Verificou-se que os três modelos se diferenciam, principalmente, quanto à estratégia adotada no tratamento dos textos; ao tipo de abordagem com a qual está relacionado, se qualitativo e/ ou quantitativo; e à postura teórica na qual se enquadra. Além disso, foi possível realizar uma comparação aos pares: Análise de Conteúdo versus Análise do Discurso; Análise de Conteúdo versus Análise de Conversação; Análise do Discurso versus Análise de Conversação. Diagnosticou-se que a "vocação naturalística" da Análise de Conversação diverge tanto da Análise de Conteúdo como da Análise do Discurso.

Uma limitação deste estudo reside no fato de que há uma dificuldade em encontrar, na literatura especializada (artigos, livros, etc.), trabalhos que se dediquem à discussão dos procedimentos necessários para se realizar uma Análise do Discurso. Com relação a esse fato, Flick (2009) leciona que, nos trabalhos publicados, predominam as alegações teóricas e os resultados empíricos. Somado a isso, a Análise do Discurso envolve um amplo e heterogêneo conjunto de teorias e práticas, assim, dificultando uma discussão mais clara e objetiva, o que poderia ser minimizado com ensaios teóricos que tenham como objetivo discutir as várias perspectivas relacionadas com esse modelo de interpretação de textos, quais sejam: Estruturalismo, Análise Foucaultiana do Discurso, Análise Semiótica do Discurso e Análise Crítica do Discurso.

É evidente, também, que boa parte dos estudos que diz empregar as técnicas de Análise de Conteúdo e Análise do Discurso não esclarece sua operacionalização, o que pode vir a prejudicar sua credibilidade, haja vista que o rigor metodológico é o que confere validade a um estudo.

A escolha de qual das técnicas de análise de dados utilizar em uma pesquisa dependerá do objeto em estudo, do campo de pesquisa e do propósito do 
pesquisador. A coexistência dos modelos em um estudo é possível, desde que haja coerência e adequação ao tema a ser estudado.

Espera-se que este estudo possa dirimir, ao menos preliminarmente, dificuldades quanto à diferenciação dos três modelos. Ressalta-se a importância da inclusão da técnica de análise das narrativas nesta discussão, que, por vezes, também, é confundida com as técnicas aqui abordadas. Recomenda-se um maior aprofundamento sobre este tema, visto que ainda são poucos os trabalhos que têm como objetivo tal diferenciação conceitual e teórico-metodológica, muito necessária para pesquisas de abordagem qualitativa, bem como para os estudos organizacionais e para pesquisadores do campo da Administração. 


\section{REFERÊNCIAS}

BARDIN, L. Análise de Conteúdo. São Paulo: Edições 70, 2011.

BINET, M. Etnografia e Análise da Conversação: Convergências e Orientações de pesquisa. Documento de Trabalho do GIID n ${ }^{\circ}$ 4. Lisboa: FCSH-UNL, 2010.

BORGES, M. L.; GONÇALO, C. R. Contribuições da Análise da Conversa aos Estudos Organizacionais. In: ENEO, 6, 2010, Florianópolis. Anais... Florianópolis: ANPAD, 2010.

BRANDÃO, H. H. N. Introdução à Análise do Discurso. 2. ed. Campinas: Editora da UNICAMP, 2004.

CAREGNATO, R. C. A.; MUTTI, R. Pesquisa Qualitativa: Análise de Discurso versus Análise de Conteúdo. Texto \& Contexto Enfermagem, Florianópolis, v. 15, n. 4, p. 679-684, out./dez. 2006.

CHIZZOTTI, A. Pesquisa qualitativa em ciências humanas e sociais. 3. ed. Petrópolis: Vozes, 2010 .

DELLAGNELO, E. H. L.; SILVA, R. C. Análise de conteúdo e sua aplicação na pesquisa em Administração. In: VIEIRA, M. M. F.; ZOUAIN, D. M. (Orgs.). Pesquisa Qualitativa em Administração: teoria e prática. Rio de Janeiro: FGV, 2005. p. 97-118.

FAGUNDES, H. S.; NOGUEIRA, V. M. R. A Análise de Discurso e Produção do Conhecimento sobre os Direitos Sociais. Sociedade em Debate, Pelotas, v. 14, n. 2, p. 185 197, jul./ dez. 2008.

FLICK, UWE. Introdução à Pesquisa Qualitativa. 3. ed. Porto Alegre: Artmed, 2009. FONSECA JÚNIOR, W. C. Análise de Conteúdo. In: DUARTE, J.; BARROS, A. (Orgs.). Métodos e Técnicas de Pesquisa em Comunicação. 2. ed. São Paulo: Atlas, 2009. p. 280-303.

KRIPPENDORFF, Klaus. Metodologia de análisis de contenido. Barcelona: Paidós, 1990. MAINGUENEAU, D. Novas tendências em Análise do Discurso. 3. ed. Campinas: Pontes, 1997.

MANHÃES, E. Análise do Discurso. In: DUARTE, J.; BARROS, A. (Orgs.). Métodos e Técnicas de Pesquisa em Comunicação. 2. ed. São Paulo: Atlas, 2009. p. 305-315.

MARCUSCHI, L. A. Análise de Conversação. 5. ed. São Paulo: Ática, 2003.

MOZZATO, A. R.; GRZYBOVSKI, D. Análise de Conteúdo como Técnica de Análise de Dados Qualitativos no Campo da Administração: Potencial e Desafios. RAC, Curitiba, v. 15, n. 4, p. 731-747, jul./ago. 2011.

PASSUELLO, C. B.; OSTERMANN, A. C. Aplicação da análise da conversa etnometodológica em entrevista de seleção: considerações sobre o gerenciamento de impressões. Estudos de Psicologia, v. 12, n. 3, p. 243-251, 2007.

ROCHA, D.; DEUSDARÁ, B. Análise de Conteúdo e Análise do Discurso: aproximações e afastamentos na (re)construção de uma trajetória. Alea: Estudos Neolatinos, Rio de Janeiro, v. 7, n. 2, p. 305-322, jul./ dez. 2005. 
SHAH, S. K.; CORLEY, K. G. Building better theory by bridging the quantitativequalitative divide. Journal of Management Sudies, v. 43, n. 8, pp. 1821-1835.

SILVA, C. R.; ANDRADE, D. N. P.; OSTERMANN, A. C. Análise da Conversa: Uma breve Introdução. ReVEL, v. 7, n. 13, p. 1-21, 2009.

SILVA, C. R.; GOBBI, B. C.; SIMÃO, A. A. O uso da Análise de Conteúdo como uma ferramenta para a pesquisa qualitativa: descrição e aplicação do método. Organizações Rurais \& Agroindustriais, Lavras, v. 7, n. 1, p. 70-81, 2005. 


\title{
DADOS DOS AUTORES
}

\author{
ANDERSON TIAGO PEIXOTO GONÇALVES ${ }^{\star}$ adm.andersontiago@gmail.com \\ Mestre em Engenharia de Produção pela UFPB \\ Instituição de vinculação: Doutorando do Programa de Pós-Graduação em \\ Administração da Universidade Federal do Rio Grande do Norte \\ João Pessoa/PB - Brasil \\ Áreas de interesse em pesquisa: Logística Empresarial, Administração da Produção e \\ Estratégia. \\ ^Rua Fernando Cunha Lima, 1845 Cristo João Pessoa/PB $\quad 58071-480$
}

